\title{
Spinal Cord Compression due to Extra Medullary Hematopoiesis in a Case of Thalassemia Minor: A Rare Case Report
}

\author{
Purwa R Patil ${ }^{1}$, Samruddhi D Rajpurkar ${ }^{1 *}$, Shantilal M Sisodia, Ajinky A Patil ${ }^{2}$ and Sanjana Ahuja ${ }^{1}$ \\ 'Dept. of Pathology, Grant Government Medical College And Sir JJ Group of Hospitals, Mumbai, India \\ ${ }^{2}$ Dept. of Radiology, Jaslok Hospital and Research Centre, India
}

\begin{abstract}
Extra medullary Hematopoiesis occurs as a result of inefficient erythropoiesis in several conditions. Para spinal Involvement is rare and it produces morbid consequences due to spinal cord compression. We present a very rare case of patient with Thalassemia Minor having Extra medullary Hematopoiesis causing Spinal cord compression followed by a detailed review of literature regarding the clinical, radiological and pathological features and treatment modalities of Extra medullary Hematopoiesis affecting predominantly the spinal region in patients with Thalassemia.
\end{abstract}

Keywords: Extramedullary Hematopoiesis; Spinal Cord Compression ; Thalassemia Minor, Review

\section{Introduction}

Extramedullary hematopoiesis (EMH) is defined as hematopoiesis that occurs in organs other than the bone marrow. Apart from physiological conditions like during fetal development, EMH occurs as a compensatory phenomenon in conditions in which there is generally a state of chronic anemia including Thalassemia, among other pathologies. ${ }^{[1]}$ EMH is mainly seen in liver, spleen and lymph nodes, pertaining to their hematopoietic activity during fetal development, but also rarely occurs in spinal region. The presence of EMH is particularly worrisome in the spinal region as it acts as a space occupying lesion (SOL) in a region that is already compromised for space, thus producing morbid consequences. The $1^{\text {st }}$ case of spinal cord compression (SCC) due to EMH in a patient with Thalassemia was reported by Gatto in 1954 , while the $1^{\text {st }}$ Indian case was reported by Prabhakar et al in $1980 .{ }^{[2]}$ Due to rarity of this entity, there is no definite consensus regarding the treatment for this condition which includes several options like surgical resection, Radiotherapy(RT), Hypertransfusion (HT), Hydroxyurea (HU) administration or a combination of the above. ${ }^{[1]} \mathrm{We}$ present a case of a 43 year old male who presented with low backache, bilateral lower limb weakness and icterus in whom EMH was suspected on intraoperative squash preparation and subsequently proven on histopathology and immunohistochemistry (IHC).

\section{Case Report}

A 43 year old Hindu male was referred to our institute with the complaints of low backache and weakness in bilateral lower limbs since 1 month without bowel and bladder disturbances. He also complained of fullness in abdomen and generalized weakness. On general examination, he appeared pale and icteric. On examination, power in the lower limbs was $4 / 5$. Lower limbs showed evidence of spasticity and hypertonia with exaggerated knee and ankle reflexes with clonus. Routine hematological investigations revealed hemoglobin $(\mathrm{Hb})$ of $7.3 \mathrm{gm} / \mathrm{dl}$ with reduced red blood cell (RBC) indices. Peripheral blood smear (PBS) revealed hypochromasia, microcytosis, anisopoikilocytosis, few target cells, basophilic stippling, polychromasia and few schistocytes suggestive of dimorphic anemia or hemolytic anemia On performing differential count, there was a neutrophilic predominance $(56 \%)$. No atypical cells were detected. (Fig 1). Serum Iron,Vit B12 and Folic Acid levels were found within the normal limits (117 ug\%, $732 \mathrm{pg} / \mathrm{ml}$, and $14 \mathrm{ng} / \mathrm{ml}$ respectively) Reticulocyte count was raised $(12 \%)$. Total bilirubin was raised (5.6 $\mathrm{mg} / \mathrm{dL}$ ), mainly the indirect fraction. Ultrasonography (USG) of the abdomen revealed hepatomegaly $(16.8 \mathrm{cms})$ and splenomegaly $(20 \mathrm{cms})$. Contrast enhanced computed tomography (CECT) spine revealed multiple homogenous, moderately enhancing soft tissue lesions within the bony spinal canal, Intradural Extramedullary(IDEM), from D5 to D8, largest measuring $13 \mathrm{X} 25 \mathrm{X} 13 \mathrm{~mm}$, causing mild SCC at D5-D6 level . Similar multiple lesions were also seen in bilateral paravertebral region from D8-D10, largest measuring $56 \mathrm{X} 15 \mathrm{X} 24 \mathrm{~mm}$, suspected to be of neoplastic etiology. EMH with marrow replacement disorder was suggested as a possibility. Magnetic resonance imaging (MRI) spine with contrast revealed these lesions to be iso to hypointense on T1, iso to hyperintense signals on T2, hyperintense signal on STIR with significant post contrast 
enhancement. (Fig.2). Impression was given as suggestive of neoplastic etiology, and it was noted that EMH was less likely in view of enhancement and T1/T2 signals. Abscess was also considered a possibility. Patient was transfused with three pints of blood preoperatively for anesthetic fitness.

With this background we received the sample labeled as tumor for intraoperative consultation. A squash preparation was done and studied that showed a cellular smear showing mixed population of cells composed of small lymphocytes, neutrophils, plasma cells, cells with increased nucleus: cytoplasmic ratio and few very large multinucleate cells. Impression was given as ?malignancy ?hematopoietic tissue (Fig 3). H\& E sections studied from the paraffin processed tissue revealed trilineage proliferation of hematopoietic cells along with fat tissue with erythroid hyperplasia (Fig 4).No atypical cells were detected Diagnosis of Extra medullary Pseudo tumor was given. IHC confirmed the diagnosis by showing cytoplasmic granular Myeloperoxidase (MPO) positivity in cells of myeloid lineage (Fig 5), CD61 intracytoplasmic positivity in megakaryocytes (Fig 6) and Glycophorin A membrane positivity in cells of erythroid series (Fig 7).

Upon reviewing past history, it was noted that patient had presented with complaints of weakness in 2012. Hemoglobin at that time ranged between 6.5- $7.7 \mathrm{gm} / \mathrm{dl}$. $\mathrm{LDH}$ levels were raised to $1301 \mathrm{U} / \mathrm{L}$ (normal- 250-430). $\mathrm{Hb}$ variant analysis was carried out by High Performance Liquid Chromatography (HPLC) method that showed raised $\mathrm{Hb} \mathrm{A} 2$ level of $5.7 \%$ (normal- 1.5-3.7\%) and normal

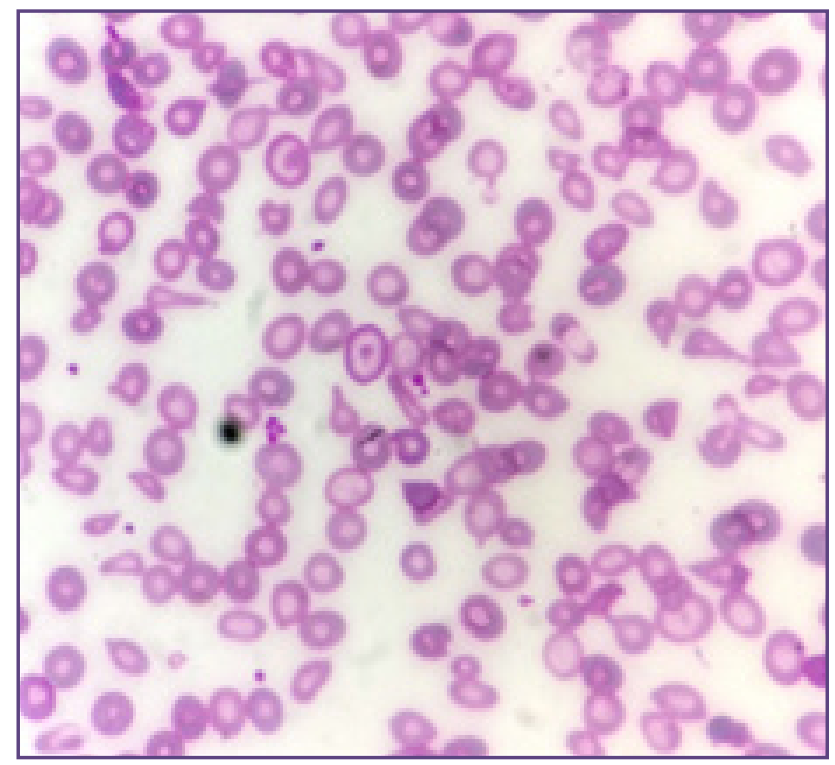

Fig. 1: PBS: Hypochromasia, Microcytosis, Anisocytosis, Target cells, Basophilic stippling (X1000x).
$\mathrm{Hb} \mathrm{F}$ levels, suggestive of Thalassemia minor trait. No other hemoglobinopathy was detected Early and delayed sickling tests were negative. Patient had been transfused with blood twice and was discharged without further counseling.

Patient received radiotherapy post-surgical decompression and is symptomatically better.

\section{Discussion}

Extra medullary hematopoiesis is defined as the hematopoiesis occurring in organs apart from the bone marrow. It can occur as a compensatory phenomenon in conditions of chronic anemia like Thalassemia, Sickle cell anemia, Hereditary spherocytosis, Myelofibrosis, Acquired hemolytic anemias, Vitamin B12 and folic acid deficiency, Bone marrow irradiation, Lymphomas as well as in condition of clonal disorder of hematopoiesis like Polycythemia Vera, Chronic Myeloid Leukemia and Myeloid Metaplasia. ${ }^{[1,3-5]} \mathrm{EMH}$ is commonly seen in organs involved in hematopoiesis in fetal life like liver or in organs of reticuloendothelial system like spleen and lymph nodes. However it is also known to occur in other organs like pleura, adrenals, breast, thymus, kidneys, gastrointestinal tract, intracranial structures, retroperitoneal tissue, sweat glands, prostate, broad ligaments, peripheral nerves, heart, retroperitoneal fat, Para spinal regions. ${ }^{[1,2,5]}$ . Para spinal location of EMH has been noted in 11-15\% cases. ${ }^{[4-7]}$ However Koch et al reported para spinal location in only $0.6 \%$ cases of EMH. ${ }^{[8]}$ Even amongst these, around $80 \%$ remain asymptomatic, detected incidentally on radiological imaging. ${ }^{[4-6]}$ The importance of para spinal

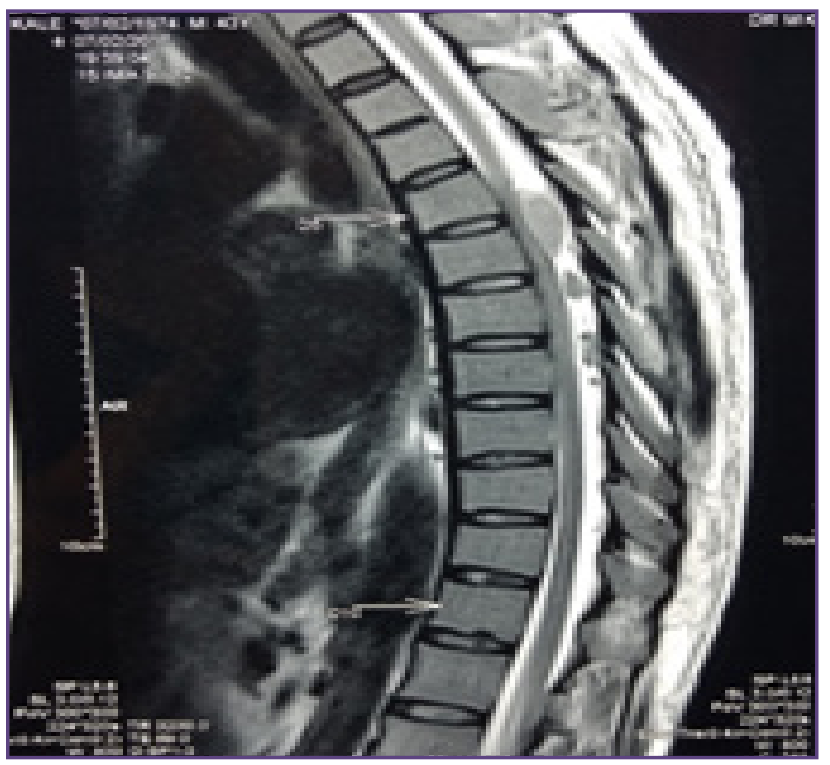

Fig. 2: MRI spine: T2W sagittal section: multiple IDEM hyperintense lesion at D5-8 vertebrae levels causing SCC. 


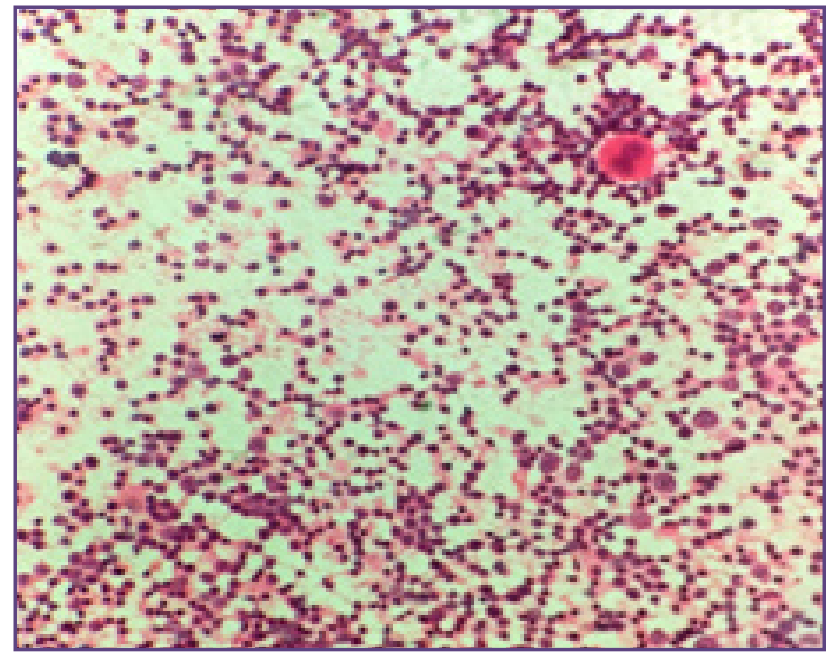

Fig. 3: Squash preparation:Triliniage proliferation of erythroid myeloid and megak ariyocyte series. (HEX 400x).

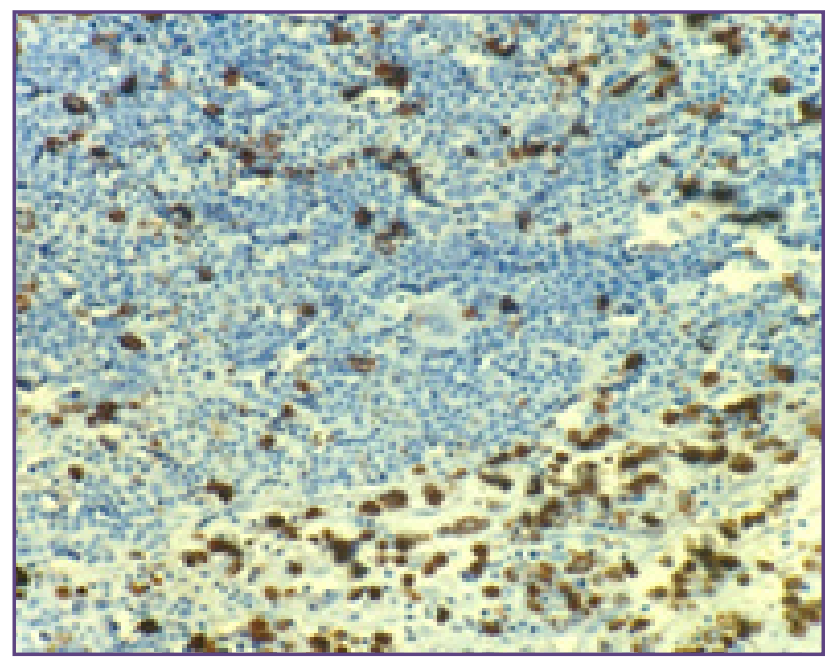

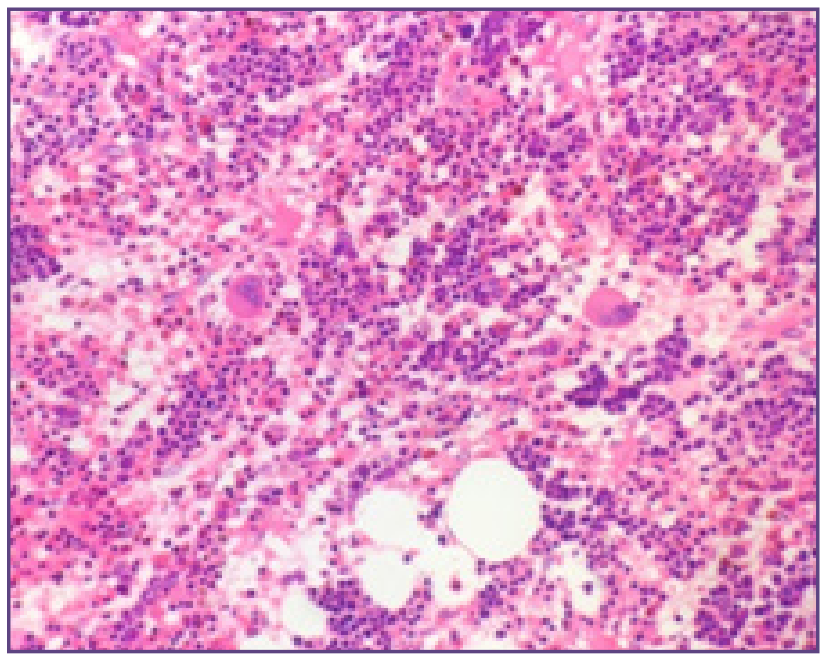

Fig 4: Histology:Triliniage proliferation of erythroid, myeloid and megakaryocyte series with adipose tissue (HE X 400x).

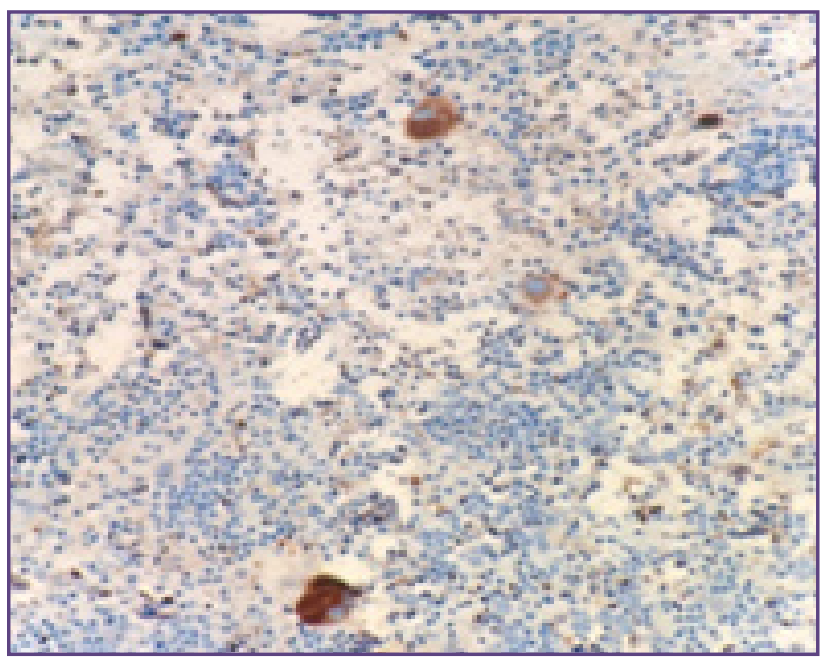

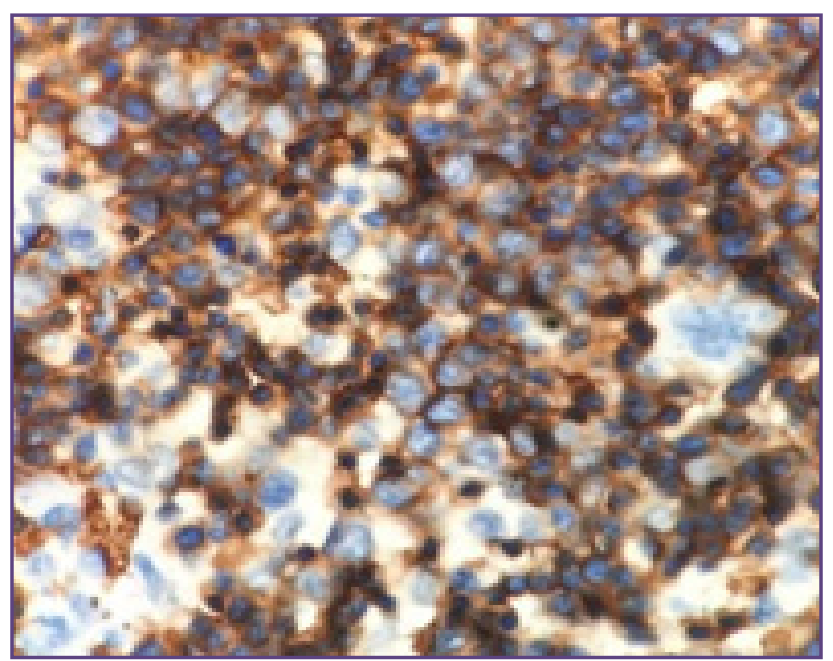

Fig. 5,6,7: Immunohistochemistry : High expression of cell sruface markers for Granulocytes (MP0 - Fig 5) Megakaryocytes (CD61-Fig. 6) and ervthroblasts (Glvcophorin A- Fig. 7) (X400x) 
EMH is that it tends to form pseudotumors behaving like a SOL and causing SCC that has considerable morbidity. Various theories that explain presence of $\mathrm{EMH}$ in para spinal region include presence of hematopoiesis in this region during fetal development that gets reactivated due to hematological stress, direct extension of hematopoietic material from medullary cavity of vertebrae, embolism and development of hematopoietic tissue from branches of intercostal veins. ${ }^{[1,4,5]}$ Thoracic and lumbar regions are most frequently affected. The exact cause for this is not known, however it adds to the morbidity as the spinal canal is quite narrow here. ${ }^{[1,4]}$ Patients with SCC secondary to EMH present mainly in the third to fourth decades of life. However similar cases have been reported in the $1^{\text {st }}$ decade suggesting that it might be affected by the severity and chronicity of the underlying disorder ${ }^{[4,5]}$ Males have a higher preponderance with sex ratios ranging from $5: 1$ to $2.5: 1 .^{[4-6]}$

Among the conditions that lead to EMH, it occurs most commonly in chronic hemolytic anemias, mainly in Thalassemia, incidence being $11-15 \% .{ }^{[1]}$ Thalassemia Intermedia was reported to have an incidence of $15-20 \%$, while it is less than $1 \%$ in cases of Thalassemia Major. ${ }^{[4,5]}$. Despite extensive literature search, to the best of our knowledge there are only two cases reported in literature of SCC due to EMH in patients with Thalassemia Minor. Beunasmananas -cervantas D reported a case of a 63 year old male with beta Thalassemia Minor with SCC caused by EMH ${ }^{[9]}$. Lalueza A et al reported case of presacral and intrathoracic EMH in a 64 year old male with Thalassemia Minor $^{[10]}$.

The patients with spinal EMH causing SCC present with a variety of motor, sensory and autonomic symptoms including drastic events like complete paralysis depending upon the location and spinal level at which the pseudotumours of EMH are present. ${ }^{[1,4]}$

Plain radiographs reveal bony changes known to occur with chronic anemic states like trabeculations, widened ribs and may reveal well defined paraspinal masses. ${ }^{[4]}$
On USG they may appear as echogenic, hypoechoeic, hypodense or heterogenous. They appear as heterogenous hypodense masses with absent, minimal or heterogenous enhancement on computed tomography (CT) . ${ }^{[3]}$ However the radiological investigation of choice is MRI. EMH appears as well defined isointense masses on T1 and T2 weighted images with variable mild to moderate contrast enhancement. ${ }^{[3]} \mathrm{MRI}$ is highly sensitivity in detecting the exact site and extent of the lesion, in demonstrating SCC and also results in lesser exposure to radiation. However, the findings may be variable in view of difference in the composition with respect to its actual hematopoietic content, adipose tissue, vascularity, iron deposits and fibrosis, which in turn depends upon chronicity of lesion and past transfusions. ${ }^{[3]}$

Differential diagnosis include Metastatic malignant neoplasms, Lymphomas, Multiple myeloma, Vascular anomalies and Epidural abscess. ${ }^{[4,6]}$ Biopsy is considered as the gold standard. However it may be complicated by calamitous hemorrhage and is generally advised when the radiological reports are inconclusive. ${ }^{[4]}$ Histopathological examination reveals mature triliniage proliferation of erythroid, myeloid and megakaryocyte proliferation along with adipose tissue. The differential diagnosis to this condition is neoplastic proliferation of myeloid lineage in which there is monomorphous population of immature myeloid cells.

Multiple treatment options have been described in literature with variable results including surgical decompression, radiotherapy (RT), hypertransfusion (HT) and hydroxyurea (HU), advantages and disadvantages of which have been given in Table 1.

It has been widely accepted that due to rarity of this disorder, more clinical trials must be carried out to determine the exact mode of treatment. Till then consensus says that the treatment should be individualized depending upon the severity of symptoms, size of masses, clinical conditions and previous treatment received.

Table 1: Advantages and Disadvantages of various treatment modalities for Spinal EMH.

\begin{tabular}{|c|c|c|}
\hline Treatment modality & Advantages & Disadvantages \\
\hline Surgical treatment & $\begin{array}{l}\text { Immediate release of SCC } \\
\text { Availability of tissue for histopathological } \\
\text { diagnosis }^{[4]}\end{array}$ & $\begin{array}{l}\text { Difficulty in complete resection due to diffuse nature } \\
\text { Increased bleeding due to highly vascular nature of } \\
\text { the lesion }{ }^{[4]} \text { Sudden clinical deterioration as these } \\
\text { tissues are responsible in maintaining the necessary } \\
\text { hemoglobin levels }{ }^{[4]} \text { Likelihood of recurrence }^{[4,7]}\end{array}$ \\
\hline Radiation & $\begin{array}{l}\text { Hematopoetic tissue is highly sensitive } \\
\text { to ionizing radiation }{ }^{[2]}\end{array}$ & $\begin{array}{l}\text { Anemia may get aggravated in some cases due to } \\
\text { decreased hematopoesis in surrounding tissue }{ }^{[1]} \\
\text { Edema of spinal cord( could be reduced by } \\
\text { simultaneous administration by steroids) })^{[4]} \\
\text { Recurrences }^{[4,6]}\end{array}$ \\
\hline
\end{tabular}




\begin{tabular}{|c|c|c|}
\hline Treatment modality & Advantages & Disadvantages \\
\hline $\mathrm{HT}$ & $\begin{array}{l}\text { Therapeutic as well as diagnostic use } \\
\text { as EMH is the only condition in which } \\
\text { patient will obtain relief due to } \mathrm{HT}^{[1,2]} \\
\text { Where both surgical management and } \\
\text { RT is not possible like in pregnancy }{ }^{[4]}\end{array}$ & $\begin{array}{l}\text { Transfusion transmitted infections, } \\
\text { Iron overload } \\
\text { Alloimmunisation } \\
\text { Recurrences }^{[4]}\end{array}$ \\
\hline $\mathrm{HU}$ & $\begin{array}{l}\text { Myelosuppresion }{ }^{[1]} \\
\text { Decrease in globin chain imbalance. }\end{array}$ & $\begin{array}{l}\text { Response to } \mathrm{HU} \text { is variable as there is associated } \\
\text { variability in genetic mutation }{ }^{[3]}\end{array}$ \\
\hline
\end{tabular}

\section{Conclusion}

To conclude, it should be kept in mind that EMH is one of the differential diagnosis in para spinal lesions which should be suspected especially when patient is known to have a hematological disorder so that suitable treatment can be undertaken. We present this case for its rarity and diagnosis on intraoperative squash preparation.

\section{Reference}

1. Wang A, Carberry N, Solli E, Gillick J, Islam H, Hillard V. Spinal Cord Compression Secondary to Extramedullary Hematopoiesis: Case Report and Review of the Literature. Case Rep Oncol. 2016 May31;9(2):290-7.

2. Singhal S, Sharma S, Dixit S, De S, Chander S, Rath GK, et al. The role of radiation therapy in the management of spinal cord compression due to extramedullary hematopoiesis in thalassaemia. J Neurol Neurosurg Psychiatry. 1992 Apr;55(4):310-2.(7)

3. Soman S, Rosenfeld DL, Roychowdhury S, Drachtman RA, Cohler A. Cord Compression due to Extramedullary Hematopoiesis in an Adolescent with Known Beta Thalassemia Major. J Radiol Case Rep. 2009 Jan4;3(1):17-22.(4)

4. Haidar R, Mhaidli H, Taher AT. Paraspinal extramedullary hematopoiesis in patients with thalassemia intermedia. Eur Spine J. 2010 Jun 5;19(6):871-8.(5)
5. Zhang H-Z, Li Y, Liu X, Chen B-R, Yao G-H, Peng Y-N. Extramedullary hematopoiesis: A report of two cases. Exp Ther Med. 2016 Dec 2;12(6):3859-62.(6)

6. Ito S, Fujita N, Hosogane N, Nagoshi N, Yagi M, Iwanami A, et al. Myelopathy due to Spinal Extramedullary Hematopoiesis in a Patient with Polycythemia Vera. Case Rep Orthop. 2017;2017:2416365.(8)

7. Musallam KM, Taher AT, Rachmilewitz EA. $\beta$-thalassemia intermedia: a clinical perspective. Cold Spring Harb Perspect Med. 2012 Jul 18;2(7):a013482.(9)

8. Koch CA, Li C-Y, Mesa RA, Tefferi A. Nonhepatosplenic extramedullary hematopoiesis: associated diseases, pathology, clinical course, and treatment. Mayo Clin Proc. 2003 Oct;78(10):1223-33(10)

9. Cervantes D B, E G-T, J S-L, V A-M, R R-C, J S-G. Extramedullary Hematopoiesis in a Non- Transfused Elderly Patient Diagnosed with Beta Thalassemia Minor. J Hematol Blood Disord. 2015;1(1):2-4.(12)

10. Lalueza A, Silva CP, Alcalá-Galiano A, Arrieta E, Cánovas JM, Calero MR, et al. Presacral and intrathoracic extramedullary hematopoiesis in a patient with $\beta$ thalassemia minor. Clin Respir J . 2016 May 5(13)

*Corresponding author:

Dr Samruddhi D Rajpurkar, 140/4760, Priti Sagar CHS, Nehru Nagar, Kurla East, Mumbai 400024, Maharashtra, India

Phone: +91 9920938939/ 02225246842

Email: drsamruddhidrajpurkar189@gmail.com

Financial or other Competing Interests: None. 